\title{
Estratificação do Jornal Vascular Brasileiro, Programas de Pós-graduação e Capes
}

\author{
Dr Winston Bonetti Yoshida*
}

Em 3 de abril de 2012, a Capes fez uma atualização do WebQualis da área de Medicina III (www.capes.gov.br/component/content/article/44.../4633-medicina-iii). Neste documento, ressaltou que a mediana dos fatores de impacto das especialidades cirúrgicas variou de 1,20 a 2,61 (Base ISI-WEB of Science) nos últimos dois anos. No entanto, apoiando-se em estudos feitos e nas propostas dos editores de revistas científicas brasileiras, em sua nova estratificação do Qualis a Capes passou a considerar não só o ISI- Web of Science, mas também o cites per doc, da base Scimago-Scopus, uma vez que foi demostrada estreita correlação entre ambos os indexadores. Ficou estabelecido neste comunicado que revistas com fator de impacto ou cites per doc $>0,01$ passariam a constar no estrato B3, sendo estratos B4 revistas indexadas em outras bases e B5 revistas de outras áreas e outras bases.

Assim, a estratificação final dos periódicos ficou de acordo com o maior valor contemplado em ambas as bases, o fator de impacto da base ISI-Web of Science e o cites per doc (dois anos), do Scimago.

Esta iniciativa trouxe vantagens para o nosso jornal. Como o J Vasc Bras não está indexado à base ISI, a estratificação do mesmo passou a ser considerada com base no cites per doc, do Scimago, onde já está indexado desde 2004.

Desta forma, o J Vasc Bras figura atualmente como estrato B3 do WebQualis da Capes (http://qualis.capes.gov.br/ webqualis/). Em outras palavras, os integrantes do Programa de Pós-Graduação da Capes poderão auferir 20 pontos por artigo publicado no J Vasc Bras, com limite de até três artigos por docente.

Entretanto, não devemos nos acomodar com este resultado, e precisamos envidar esforços no sentido de crescimento da estratificação no WebQualis da Capes. Neste sentido, conclamamos todos os autores e revisores do J Vasc Bras a citar artigos do nosso jornal, seja nos artigos do próprio J Vasc Bras como também em publicações de outras revistas.
Para alcançarmos o estrato B2 precisaremos de cites per doc $>0,90$; para o estrato B1, cites per doc > 1,50; para estratos $\mathrm{A} 2$, cites per doc $>2,63$; e para A1, cites per doc $>3,30$.

Na Figura 1, verificamos a evolução do cites per doc do J Vasc Bras de 2004 a 2011. Constatamos que de 2004 a 2008 houve crescimento progressivo das citações, mas infelizmente, a partir de 2008, houve uma queda. Já há muito tempo vem se chamando a atenção dos autores e revisores do J Vasc Bras sobre este problema ${ }^{1,2}$.

É bastante fácil encontrar artigos relacionados com os temas. Basta digitar na janela da página inicial do jornal (www. jvascbr.com.br) o tema ou palavra-chave, ou mesmo o nome do autor de interesse. Em segundos abre-se uma lista de artigos potencialmente citáveis do J Vasc Bras (Figura 2).

Concluindo, é preciso concentrar esforços de todos para ajudar no crescimento do nosso jornal, principalmente incrementando o número de submissões e fazendo as devidas citações de sua produção.

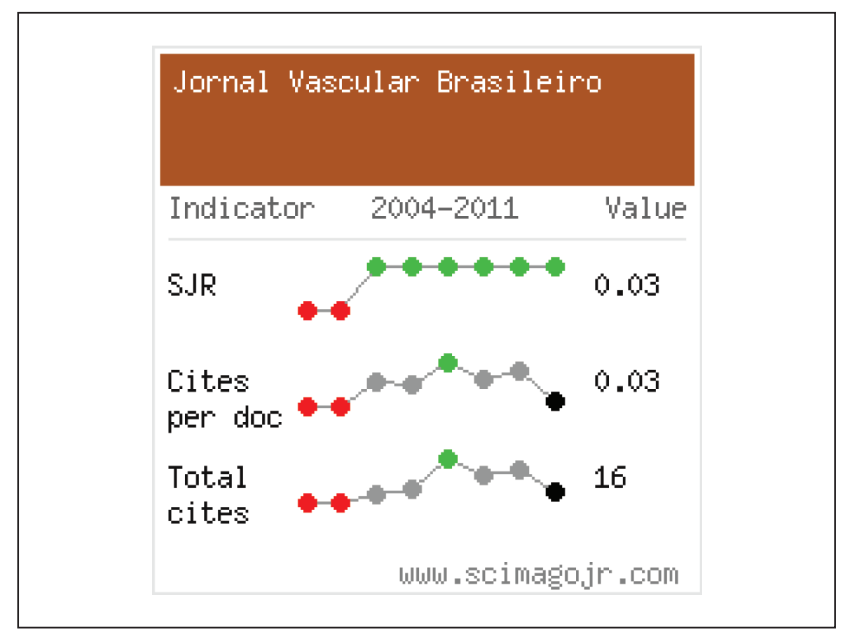

Figura 1. citações do J Vasc Bras de 2004 a 2011 de acordo com Scimago (http://www.scimagojr.com/index.php). 


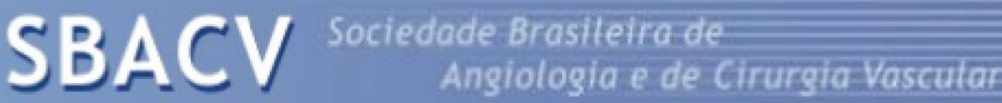

\section{JORNAL VASCULAR BRASILEIRO}

Cirurgia Vascular, Endovascular e Angiologia

ISSN 1677-5449

Agora com submissão online: http://submission.scielo.br/index.php/jvb/index Now with an online submission system: http://submission.scielo.br/index.php/jvb/index

CORPO EDITORIAL

editors

CONSELHO EDITORIAL editorial board

CONSELHO INTERNACIONAL international advisory board

DIRETORIA NACIONAL SBACV national board SBACV

PUBLICAÇÃO DIGITAL online publication

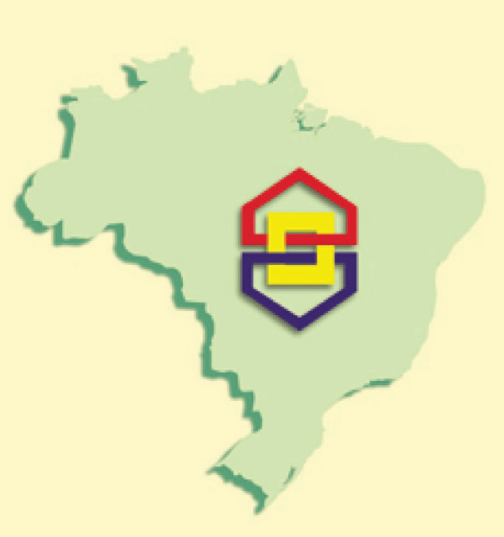

EDIÇÃO ATUAL current issue

EDIÇÕES ANTERIORES previous issues

NORMAS DE PUBLICAÇÃO publication guidelines

CONTATO contact us

LINKS

J Vasc Bras is indexed in the following data bases: SciELo (Scientific Electronic Library Online), LILACS (Literatura Latino-Americana do Caribe em Ciências da Saúde), SIIC (Sociedad Iberoamericana de Información Cientifica), EBSCO Publishing, Elsevier's Bibliographic Databases EMBASE and SCOPUS, and Redalyc (Red de Revistas Cientifficas de América Latina y El Caribe, España y Portugal).

Figura 2. Página do J Vasc Bras com janela para busca de referências, (www.jvascbr.com.br).

\section{Referências}

1. Yoshida WB. The impact factor of Jornal Vascular Brasileiro.J Vasc Bras. 2008;7:187-188. http://dx.doi.org/10.1590/S1677-54492008000300001

2. Costa-Val R, Sousa Filho J. A produção científica do J Vasc Bras: conquistas e desafios. J Vasc Bras. 2008;7:6-17. http://dx.doi.org/10.1590/ S1677-54492008000100004 